\title{
PENURUNAN KANDUNGAN BAKTERI ESCHERICHIA COLI DAN TIMBAL PADA AIR BERSIH MENGGUNAKAN MEMBRAN REVERSE OSMOSIS
}

\section{Peni Mardiatin**) dan Setyo Purwoto*)}

\begin{abstract}
Abstrak
Tujuan dari penelitian ini adalah mengetahui kandungan bakteri Escherichia Coli (e. coli) dan timbal $(\mathrm{Pb})$ sebelum dan setelah dilakukan pengolahan dengan membran Reverse Osmosis (ro) serta efektifitas penurunan kandungan E. Coli dan timbal (Pb) setelah pengolahan. Sampel penelitian yaitu air sumur bor. Dalam penelitian ini membran yang digunakan adalah CSM model no. RE2012-100. Pengolahan dilakukan dengan mengalirkan air sampel dengan bantuan boostpump melalui membran reverse osmosis dengan tekanan yang berbeda; 43 psi, 50 psi, 57 psi, dan 64 psi. Setelah didapatkan hasilnya kemudian dilakukan pemeriksaan laboratorium lagi untuk mengetahui efektifitas membran RO. Dalam penelitian ini didapatkan hasil bahwa membran reverse osmosis mampu menurunkan kandungan bakteri E. Coli sampai $91 \%$ yaitu dari 88 kol/100 $\mathrm{ml}$ menjadi $8 \mathrm{kol} / 100 \mathrm{ml}$ pada tekanan 43 psi dan kadar timbal sampai 96\% yaitu dari 9,4 mg/l menjadi 0,4 mg/l pada tekanan 43 psi. Dengan tekanan yang besar debit air yang dihasilkan akan besar, tekanan yang kecil debit yang dihasilkan juga kecil. Sebelum menggunakan membran reverse osmosis (RO) sebaiknya dilakukan pengolahan dengan mengalirkan air melalui filter lain guna menjaga agar membran RO tidak cepat buntu yang akan mempengaruhi kualitas air yang dihasilkan nantinya.
\end{abstract}

Kata kunci : Air bersih, Bakteri Escherichia Coli (E. Coli ), timbal (Pb), membran reverse osmosis, tekanan.

\section{PENDAHULUAN}

Air minum mempunyai beberapa syarat yang harus terpenuhi agar bisa digunakan untuk memenuhi kebutuhankebutuhan lainnya. Standar baku mutu ditentukan berdasarkan keputusan Menteri Kesehatan Republik Indonesia No. 492/Menkes/PER/2010 tentang persyaratan kualitas air minum. Di Desa Tempel Kecamatan Krian Kabupaten Sidoarjo ada beberapa sumur yang kandungan E. Coli dan timbalnya melebihi standart baku mutu air.

Dari segi geografis, Desa Tempel terletak di kawasan daerah industri sehingga tidak menutup kemungkinan daerah tersebut juga akan terkontaminasi oleh limbah logam berat dari industri, antara lain timbal $(\mathrm{Pb})$.

Berdasarkan hasil pemeriksaan bakteriologis dan kemungkinan tejadinya pencemaran industri yang bisa mempengaruhi kualitas air, maka harus dilakukan pengolahan, yang antara lain bisa dengan menggunakan membran Reverse Osmosis. Maka dalam kesempatan ini penulis akan melakukan penelitian tentang penurunan kandungan bakteri Escherichia coli dan timbal $(\mathrm{Pb})$ pada air bersih dengan menggunakan membran reverse osmosis (RO) sehingga air tersebut bisa memenuhi syarat kesehatan.
Di air, mikrobiologi bisa berkembang biak dan juga sebagai tempat tinggal sementara sebelum mikrobiologi tersebut berpindah ke manusia atau mahkluk hidup lain. Escherichia coli atau sering disebut E. Coli berasal dari kotoran manusia dan hewan (tinja). Tinja tersebut merembes ke dalam tanah dan bisa mencemari sumber air. Menurut Staf Pengajar Fakultas Kedokteran Universitas Indonesia, penyakitpenyakit yang disebabkan oleh Escherichia coli adalah : Penyakit diare, infeksi saluran kemih, pneumonia, meningitis pada bayi baru lahir dan infeksi luka terutama luka di dalam abdomen.

Sedangkan logam timbal $(\mathrm{Pb})$ dan persenyawaannya dapat berada di dalam badan perairan secara alamiah dan sebagai dampak dari aktivitas manusia. $\mathrm{Pb}$ yang masuk ke dalam perairan sebagai dampak aktivitas kehidupan manusia diantaranya adalah air buangan dari pertambangan bijih timah hitam, buangan sisa industri baterai dan bahan bakar angkutan air. Secara alamiah, $\mathrm{Pb}$ dapat masuk ke badan perairan melalui pengkristalan $\mathrm{Pb}$ di udara dengan bantuan air hujan.

\footnotetext{
**) Mahasiswa Teknik Lingkungan

*) Dosen Teknik Lingkungan

Universitas PGRI Adi Buana Surabaya
} 
Selain itu, proses korosifikasi dari batuan mineral akibat hempasan gelombang dan angin, juga merupakan salah satu jalur sumber $\mathrm{Pb}$ yang akan masuk dalam badan perairan. Senyawa $\mathrm{Pb}$ yang ada dalam badan perairan dapat ditemukan dalam bentuk ion-ion divalen atau ion-ion tetravalen $(\mathrm{Pb} 2+, \mathrm{Pb} 4+)$. Badan perairan yang telah kemasukan senyawa atau ion-ion $\mathrm{Pb}$, sehingga jumlah $\mathrm{Pb}$ yang ada dalam badan perairan melebihi kosentrasi yang semestinya, dapat mengakibatkan kematian bagi biota perairan.

Reverse osmosis (RO) adalah teknologi pemurnian air yang menggunakan membran semipermeabel. Dalam proses osmosis normal, pelarut alami bergerak dari area dengan konsentrasi zat terlarut rendah (Potensi Air Tinggi), melalui membran, ke daerah konsentrasi zat terlarut tinggi (Potensi Air Rendah). Pergerakan pelarut murni didorong untuk mengurangi energi bebas dari sistem dengan menyamakan konsentrasi zat terlarut pada setiap sisi membran, menghasilkan tekanan osmotik. Reverse osmosis melibatkan mekanisme difusif sehingga efisiensi pemisahan tergantung pada konsentrasi zat terlarut tekanan, dan laju aliran air seperti yang terlihat dalam gambar 1 ini.

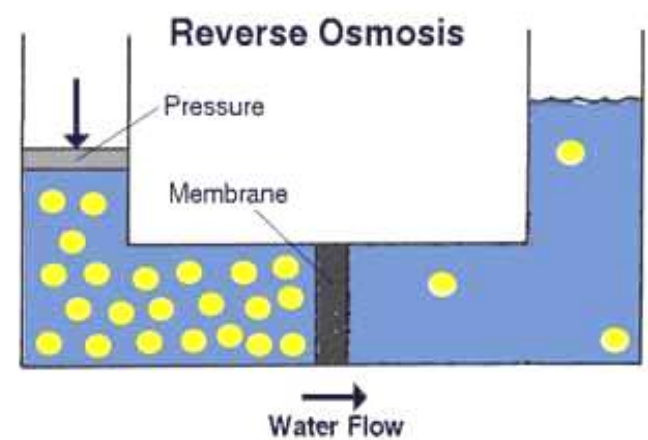

Gambar 1. Skema Proses Reverse Osmosis

Teknologi membran RO mempunyai keunggulan antara lain : pengolahan dapat dilakukan secara kontinyu, konsumsi energi relatif rendah, mudah digabung dengan proses pemisahan lainnya, dapat dilakukan dengan kondisi operasi yang dapat diatur, tidak memerlukan bahan tambahan, dan material penyusun membran yang bervariasi.

\section{METODE PENELITIAN}

Lokasi dan waktu

Penelitian ini dilakukan di Desa

Tempel, Kecamatan Krian, Kabupaten Sidoarjo, Jawa Timur. Pelaksanaan penelitian ini selama 3 bulan yaitu Bulan Nopember 2013 sampai dengan Bulan Januari 2014.

Varibel

Parameter dalam penelitian ini adalah kandungan bakteri Escherichia Coli (E. Coli) dan timbal (Pb). Sedangkan variabel bebasnya adalah tekanan yang digunakan (43 psi, 50 psi, 57 psi, 64 psi) . Alat dan bahan yang digunakan :

Boostpump, selang $1 / 4$ ", manometer, membran $\mathrm{RO}$, valve, dan flow restrictor Langkah penelitian :

Air baku ditampung dalam tandon. Air mulai mengalirkan melalui selang ke Boost pump. Boost pump menekan air tersebut yang kemudian mengalir melalui percabangan dimana yang satu dipasang valve yang berfungsi sebagai pengatur tekanan air dan dialirkan lagi ke air baku, dan yang satunya disambungkan dengan manometer. Dari manometer lalu disambungkan ke membran RO. Air yang lolos melewati pori membran $\mathrm{RO}$ akan mengalir menuju ke penampungan hasil pengolahan. Sedangkan air yang tidak dapat melewati pori membran $\mathrm{RO}$ keluar melalui selang yang telah dipasang flow restrictor dan dialirkan ke penampungan sisa pengolahan.

Adapun rancangan disain penelitian yang dilakukan dengan menggunakan sistem reverse osmosis ini seperti pada gambar 2. berikut ini: 


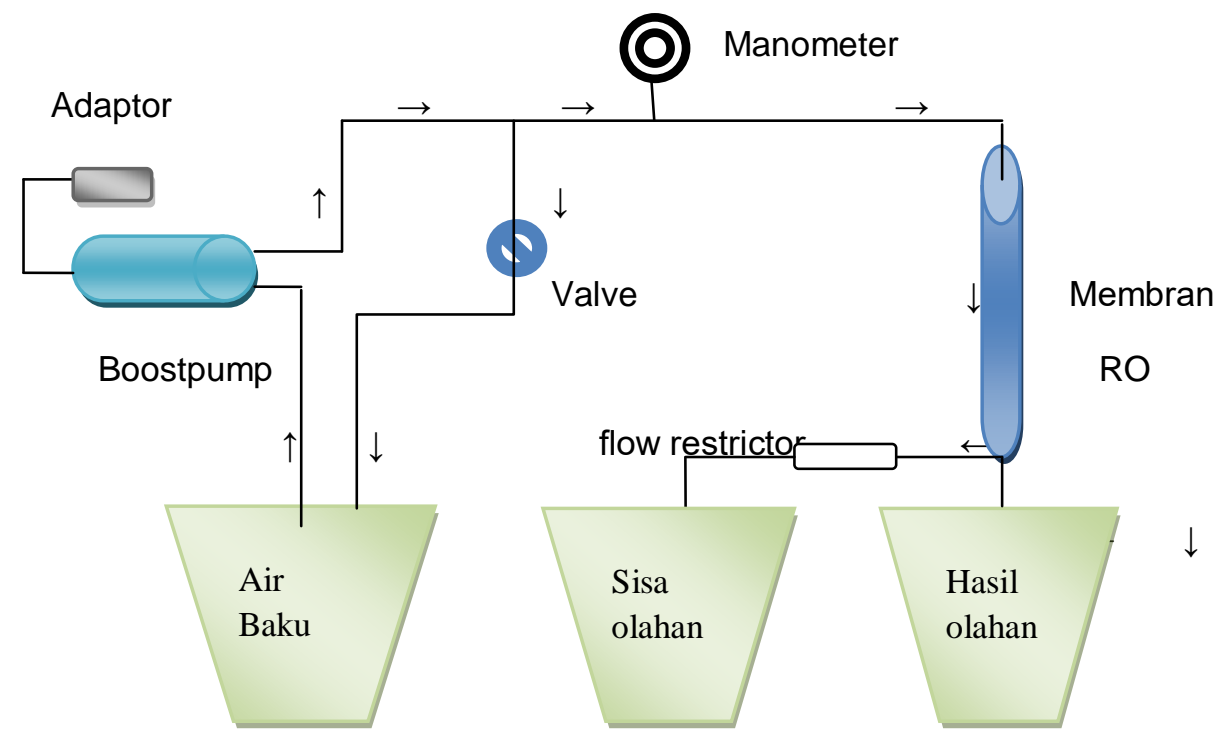

Gambar 2. Diagram alir reactor

\section{Pemeriksaan laboratorium}

Pemeriksaan laboratorium dilakukan untuk mengetahui parameter kandungan bakteri E.Coli dengan menggunakan metode APM dengan satuan $\mathrm{kol} / 100 \mathrm{ml}$, dan timbal $\mathrm{Pb})$ dengan metode analisa sulfit dengan satuan $\mathrm{mg} / \mathrm{l}$, yang dilaksanakan di BPKI (Balai Penelitian dan Konsultasi Industri) Surabaya.

Analisis data

Data hasil uji laboratorium sampel akan dihitung dengan membandingkan hasil uji sampel awal dengan hasil uji sampel akhir untuk mengetahui tingkat efisiensi penurunan kandungan bakteri E. Coli dan kadar timbal dengan metode tabel dan grafik.

\section{HASIL PENELITIAN}

Setelah dilakukan pengolahan dengan menggunakan membran RO didapatkan hasil pengamatan pemeriksaan laboratorium kandungan bakteri E. Coli seperti pada tabel 1 ini :

Tabel 1. Efisiensi Penurunan Kandungan Bakteri E. Coli setelah dilakukan pengolahan menggunakan membran $\mathrm{RO}$

\begin{tabular}{cccccc}
\hline Tekanan & Waktu Operasi & Debit & \multicolumn{2}{c}{$\begin{array}{c}\text { Kandungan E.Coli dalam } \\
\text { kol/100ml }\end{array}$} & $\begin{array}{c}\text { Efisiensi } \\
\text { Penurunan }\end{array}$ \\
\cline { 2 - 6 } & (menit) & ml/detik & Awal & Hasil & $\%$ \\
\hline \multirow{2}{*}{43 psi } & 10 & 2,0 & 88 & 8 & 90,91 \\
& 20 & 2,10 & 88 & 9 & 89,77 \\
50 psi & 30 & 2,0 & 88 & 8 & 90,91 \\
& 10 & 2,25 & 88 & 11 & 87,50 \\
57 psi & 20 & 2,15 & 88 & 9 & 89,77 \\
& 10 & 2,20 & 88 & 10 & 88,64 \\
& 10 & 2,55 & 88 & 31 & 64,77 \\
64 psi & 20 & 2,40 & 88 & 26 & 70,45 \\
& 10 & 2,45 & 88 & 28 & 68,18 \\
& 10 & 2,75 & 88 & 65 & 26,14 \\
& 30 & 2,65 & 88 & 61 & 30,68 \\
& 30 & 2,70 & 88 & 62 & 29,55 \\
\hline
\end{tabular}

Dari pengamatan pemeriksaan laboratorium seperti pada tabel 1. diatas dapat dilihat penurunan kandungan E. Coli dan efisiensi penurunan kandungan E. Coli dimana dengan tekanan 64 psi efisiensinya bisa $29 \%$ dan dengan tekanan rendah yaitu 43 psi efisiensi kandungan bakteri E. Coli bisa sampai $91 \%$. Penurunan kandungan bakteri E. Coli dan efektifitasnya bisa dilihat 
dalam grafik seperti pada gambar 3 dan 4 ini.

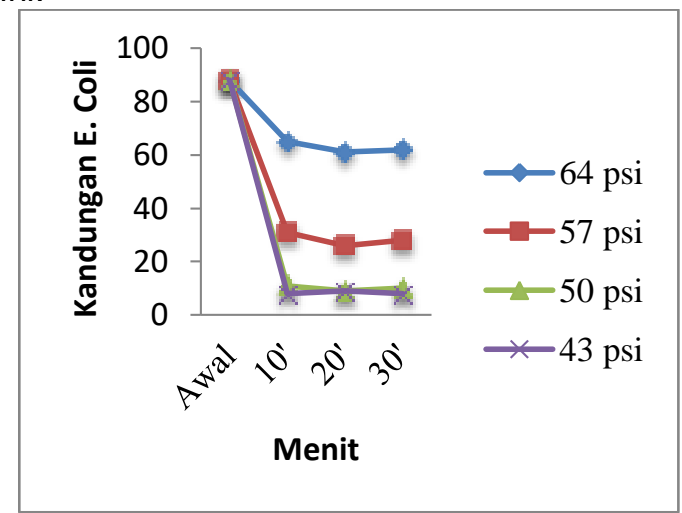

Gambar 3. Grafik Penurunan Kandungan E. Coli Setelah Pengolahan dengan Membran $\mathrm{RO}$

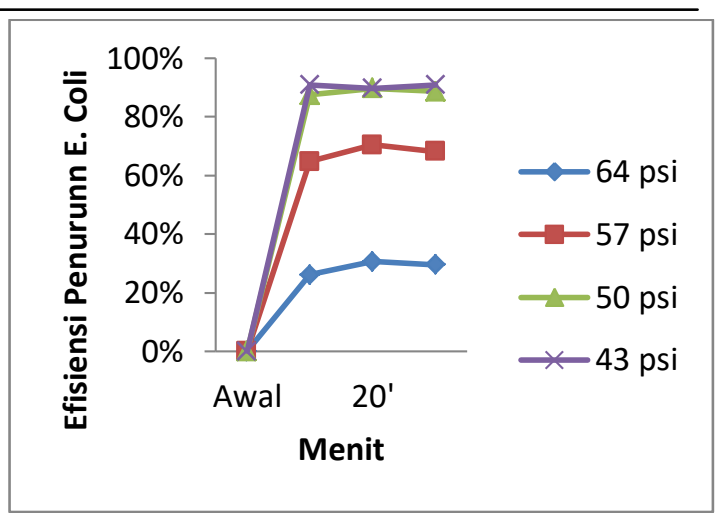

Gambar 4. Grafik Efisiensi Penurunan Kandungan Bakteri E. Coli dalam Persen Setelah Dilakukan Pengolahan dengan Membran RO

Sedangkan untuk kadar timbal, setelah dilakukan pengolahan dengan menggunakan membran $\mathrm{RO}$ didapatkan hasil pengamatan pemeriksaan laboratorium kadar timbal $(\mathrm{Pb})$ seperti pada tabel 2 ini :

Tabel 2. Efisiensi Penurunan Kadar Timbal (Pb) setelah dilakukan pengolahan menggunakan membran RO

\begin{tabular}{cccccc}
\hline \multirow{2}{*}{ Tekanan } & Waktu Operasi & Debit & \multicolumn{2}{c}{ Kandungan E.Coli dalam } & $\begin{array}{c}\text { Efisiensi } \\
\text { Pol/100ml }\end{array}$ \\
\cline { 2 - 6 } & (menit) & ml/detik & Awal & Hasil & $\%$ \\
\hline \multirow{2}{*}{43 psi } & 10 & 2,0 & 9,4 & 0,3 & 96,81 \\
& 20 & 2,10 & 9,4 & 0,4 & 95,74 \\
50 psi & 30 & 2,0 & 9,4 & 0,4 & 95,74 \\
& 10 & 2,25 & 9,4 & 0,4 & 95,74 \\
57 psi & 20 & 2,15 & 9,4 & 0,5 & 94,68 \\
& 30 & 2,20 & 9,4 & 0,6 & 93,62 \\
& 10 & 2,55 & 9,4 & 3,0 & 68,09 \\
64 psi & 20 & 2,40 & 9,4 & 3,6 & 61,70 \\
& 10 & 2,45 & 9,4 & 3,3 & 64,89 \\
& 20 & 2,75 & 9,4 & 6,0 & 36,17 \\
& 30 & 2,65 & 9,4 & 5,8 & 38,30 \\
& 2,70 & 9,4 & 6,2 & 34,04 \\
\hline
\end{tabular}

Dari pengamatan pemeriksaan laboratorium seperti pada tabel 2. dapat dilihat penurunan kadar timbal $(\mathrm{Pb})$ dan efisiensi penurunan kadar timbal $(\mathrm{Pb})$ dimana dengan tekanan 64 psi efisiensinya bisa sampai $36 \%$ dan dengan tekanan rendah yaitu 43 psi efisiensi penurunan kadar timbal $(\mathrm{Pb})$ bisa sampai $96 \%$. Dari hasil pengamatan pemeriksaan laboratorium tersebut penurunan kadar timbal dan efisiensinya bisa digambarkan dalam grafik seperti pada gambar 5 dan 6 berikut ini:

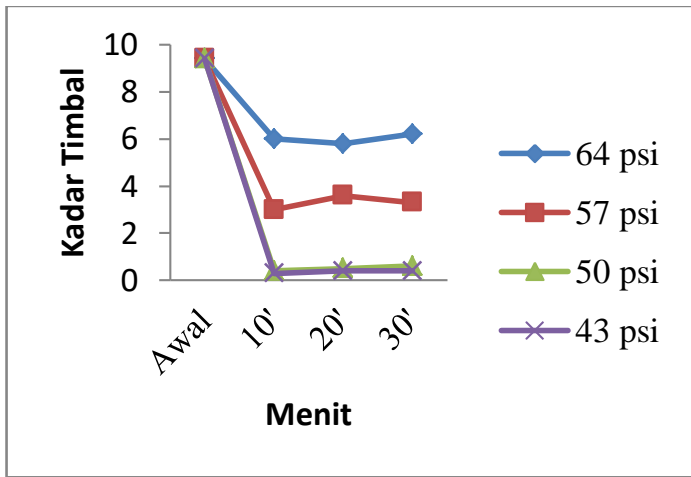

Gambar 5. Grafik Penurunan Kadar Timbal (Pb) Setelah Pengolahan dengan Membran $\mathrm{RO}$ 


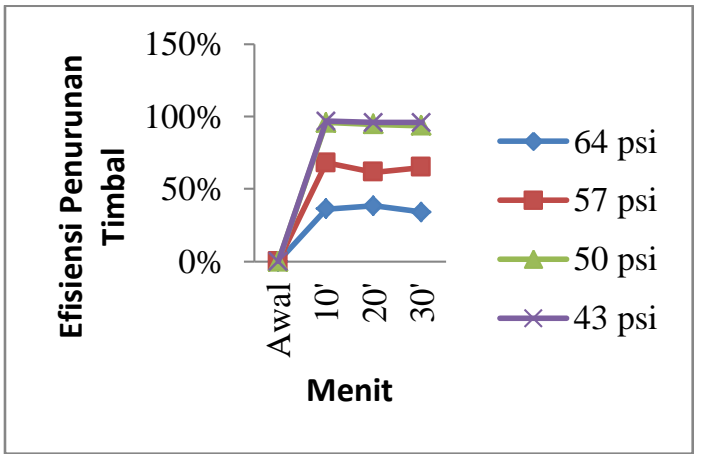

Gambar 6. Grafik Efisiensi Penurunan Kadar Timbal $(\mathrm{Pb})$ dalam Persen Setelah Dilakukan Pengolahan dengan Membran RO

Seperti yang telah dijelaskan sebelumnya bahwa perbedaan tekanan yang diberikan pada membran mempengaruhi debit yang dihasilkan. Mengacu pada tabel 1 dan 2, maka pengaruh tekanan terhadap debit bisa digambarkan pada grafik berikut :

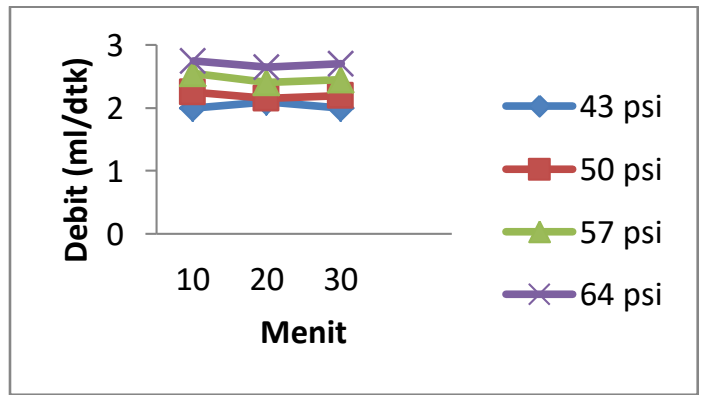

Gambar 7. Grafik pengaruh tekanan terhadap debit yang dihasilkan

\section{PEMBAHASAN}

Pada saat dilakukan pengolahan menggunakan membran RO dengan tekanan yang berbeda maka debit yang dihasilkan juga akan berbeda, dan kualitasnya pun akan berbeda juga. Dengan tekanan yang lebih besar maka debit yang dihasilkan juga lebih besar. Pada tekanan yang lebih kecil debit yang dihasilkan juga akan lebih kecil. Dengan debit kecil maka air akan semakin lama melewati membran dan partikel pun akan lebih banyak yang tersaring. Dengan demikian hasilnya akan lebih baik. Dalam penelitian ini pada tekanan 43 psi merupakan tekanan yang optimal karena efektifitasnya paling tinggi.

Penurunan kandungan bakteri $\mathrm{E}$. Coli dan timbal relatif stabil dalam tekanan yang sama, ini dikarenakan pencucian alat dilakukan setiap pergantian tekanan, atau setelah $3 x$ pengambilan sampel.
Berdasarkan hasil penelitian ini menunjukkan bahwa telah terjadi penurunan kandungan bakteri E. Coli dan kadar timbal dengan menggunakan membran $\mathrm{RO}$, namun belum memenuhi standar baku mutu sebagai air minum. Hal ini bisa terjadi karena ada beberapa faktor yang mempengaruhi osmosis antara lain temperatur, zat terlarut, dan tebalnya membran. Atau bisa juga karena kesalahan teknis dimana pada saat membuka membran dari bungkusnya dan akan dimasukkan ke dalam housing, tangan yang memegang dalam keadaan kurang bersih.

Pada proses pemisahan menggunakan RO, membran akan mengalami perubahan karena memampat dan menyumbat (fouling). Pemampatan atau fluks merosot itu serupa dengan perayapan plastik/logam ketika terkena beban tegangan kompresi. Makin besar tekanan dan suhu biasanya membran makin mampat dan menjadi tidak reversible. Normalnya membran bekerja pada suhu 21-35 derajat Celcius. Fouling membran dapat diakibatkan oleh zat-zat dalam air baku seperti kerak, pengendapan koloid, oksida logam, bahan organik dan silika. Oleh sebab itu cairan yang masuk ke proses reverse-osmosis harus terbebas dari partikel-partikel besar agar tidak merusak membran. Pada prakteknya, cairan sebelum masuk ke proses reverse-osmosis dilakukan serangkaian pengolahan terlebih dahulu, biasanya dilakukan pretreatment dengan koagulasi dan flockulasi yang dilanjutkan dengan adsorbsi karbon aktif dan mikrofiltrasi.

Pada suatu saat membran akan mengalami kotor, akibat dari adanya material-material yang tidak bisa lewat. Hal ini yang menyebabkan tersumbatnya membran. Kotoran yang terbentuk gumpalan kotoran, kerak atau hasil proses hidrolisa. Untuk mengembalikan kekondisi semula dilakukan pembersihan dengan menggunakan larutan pembersih yang khusus. Bahan ini bisa melarutkan kotoran tetapi tidak merusak membran yang biasanya terbuat dari enzim. Proses pencucian dilakukan dengan meresirkulasi larutan pencuci ke membran.

\section{KESIMPULAN}

Berdasarkan penelitian yang dtelah dilakukan maka bisa diambil kesimpulan :

Dengan menggunakan membran $\mathrm{RO}$ kandungan bakteri E. Coli efisiensi penurunannya $91 \%$ yang terjadi pada 
tekanan $43 \mathrm{psi}$, dan kadar timbal $(\mathrm{Pb})$ efisiensi penurunannya $96 \%$ yang terjadi juga pada tekanan 43 psi.

Pada penelitian ini efisiensi membran RO dalam menurunkan kandungan bakteri E. Coli sudah bagus bisa sampai $8 \mathrm{kol} / 100 \mathrm{ml}$ tetapi belum memenuhi syarat sebagai air minum yang semestinya 0 $\mathrm{kol} / 100 \mathrm{ml}$, tetapi sudah memenuhi syarat sebagai air bersih yaitu kandungan E. Coli maksimum yang diperbolehkan adalah 10 $\mathrm{kol} / 100 \mathrm{ml}$. Dan untuk kadar timbal $(\mathrm{Pb})$ turun menjadi $0,3 \mathrm{mg} / \mathrm{l}$ masih belum bisa memenuhi syarat sebagai air bersih dan air minum yaitu kadar timbal maksimum yang diperbolehkan adalah $0,05 \mathrm{mg} / \mathrm{l}$

\section{SARAN}

Dengan mengetahui hasil penelitian ini maka perlu diperhatikan:

Menggunakan membran RO merupakan suatu pemanfaatan teknologi yang bisa membantu manusia dalam menyediakan kebutuhan akan air bersih dan air minum. Akan tetapi teknologi ini membutuhkan dana yang cukup banyak sehingga belum bisa digunakan oleh seluruh lapisan masyarakat, dan air yang dihasilkan relatif sedikit.

Pengolahan air dengan menggunakan membran RO sebaiknya ada filter atau penyaring lain sebelumnya agar membran RO tidak mudah buntu yang akan mempengaruhi kualitas membran dan debit air yang dihasilkan.

\section{DAFTAR PUSTAKA}

Admin, 2012, Teknologi Pengolahan Air. http://tokohydro.com/artikel/teknologi-pengolahan-air.html (tanggal mengunduh : 4 April 2013)

Aji, Bayu Panji, 2010, Kajian Kualitas Air Tanah ditinjau Dari Parameter Bakteri Escherichia Coli (E. Coli)

Departemen Kesehatan RI, 2010, Peraturan Menteri Kesehatan RI Nomor :

492/MENKES/PER/IV/2010, Tentang Syarat-syarat dan Pengawasan Kualitas Air Minum, Jakarta

Firdaus, Muhammad Yusuf, 2012, Teknologi Membran, diunduh tanggal 11 September 2014

Grahapermana19.blogspot.com/..../bahaya-bakteri-ecoli (tanggal mengunduh : 3 Nopember 2013 http://pengolahanair.com/?page =pt artikel\&ida=1074\&judul=PENGOLAHAN AIR BERSIH tanggal posting 18 Januari 2013

http://Indobeta.com/tentang-bakteri-escherichia-coli/9140 (tanggal mengunduh : 14 Juni 2013). Juliardi, Naniek Ratni AR, 2005, Peningkatan Kualitas Air Minum Menggunakan Membran Reverse

Osmosis.(tanggal mengunduh : 6 Oktober 2013)

Mania Bgt, Luqman, 26 Juli 2012, Makalah Difusi Osmosis, diunduh tgl 31 Agustus 2014

Munif, helpingpeopleideas.com/...meriksaan-bakteriologis-air. Diunduh tanggal 11 Desember 2013 